\title{
OVERVIEW ON HYBRID PROPULSION
}

\section{Calabro}

The Inner Arch

Rue Saint Sébastien 4, Poissy, France

\begin{abstract}
Aside of research works, this historical survey shows propulsion units used by students for small satellites and for gas generation, or those for the Space Ship One, even if LOx/HTPB was studied and tested in large motors for its potential very low cost; however, this combination highlights a series of technical problems without any performance advantage over the existing $\mathrm{LOx} /$ Kerosene family and never been operational for ETO applications. The particularity of hybrid propulsion is to use the state-of-the-art of both liquids and solids; the only show stopper is the propellant itself. The past work focused on LOx/HTPB (selected for its low cost) appears to be a dead-end (combustion problems and global low performances resulting from a high level of residuals). The solution that appears through the past experience is the addition of hydrides to a binder (HTPB or other) or to a binder and a homogeneous fuel or a mixture of both, with or without others additives; within these solutions some will not present any manufacturing problem and some may have a low cost. Nevertheless, the studies of the following phases have to demonstrate the compatibility of the potential regression rate range with a high-performance global design of a hybrid Motor and the manufacturing at a reasonable cost of a hydride giving a high level of performances.
\end{abstract}

\section{NOMENCLATURE}

ETO Earth To Orbit

HTM Hybrid Test Motor

LEO Low Earth Orbit

\section{Chemical Acronyms}
AN Ammonium nitrate
AP Ammonium perchlorate
CTPB Carboxyl terminated polybutadiene
DCPD Dicyclopentadiene

\footnotetext{
This is an Open Access article distributed under the terms of the Creative Commons Attribution-Noncommercial License 3.0, which permits unrestricted use, distribution, and reproduction in any noncommercial medium, provided the original work is properly cited.
} 


$\begin{array}{ll}\text { GAP } & \text { Glycidyle Azide Polymer } \\ \text { GOx } & \text { Gaseous Oxygen } \\ \text { HTPB } & \text { Hydroxyl-Terminated PolyButadiene } \\ \text { LOx } & \text { Liquid Oxygen } \\ \text { NMTD } & \text { Nylon Metatoluene Diamine } \\ \text { PB } & \text { PolyButadiene } \\ \text { PBAN } & \text { PolyButadiene AcryloNitrile } \\ \text { PE } & \text { PolyEthylene } \\ \text { PEG } & \text { PolyEthylene Glycol } \\ \text { PMMA } & \text { PolyMethyl MethAlcrylate } \\ \text { PS } & \text { PolyStyrene } \\ \text { PU } & \text { PolyUrethane }\end{array}$

\section{INTRODUCTION}

When one propellant is a solid and the other one is a liquid, a rocket motor is designated as hybrid architecture. Most of chemical rocket motors require at least two reacting media: a fuel and an oxidizer to burn and produce hot gases. The hybrid rocket may be classified into various types as shown in Fig. 1. The standard hybrid motor arrangement consists of a pure fuel grain casted and cured in the combustion chamber (as a solid rocket motor) and of a liquid oxidizer stored in a separate tank and injected under pressure in the combustion chamber (several configurations exist depending on the propellants and the ap-

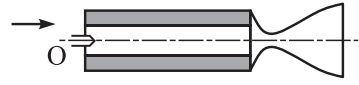

(a)

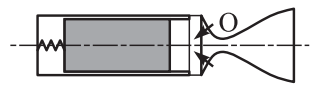

(b)

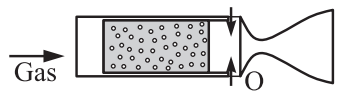

(c)

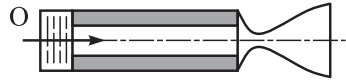

(d)

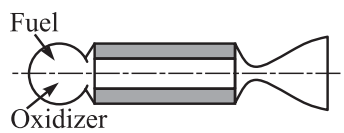

(e)

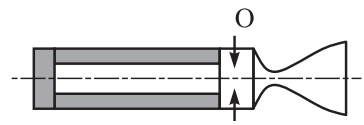

(f)

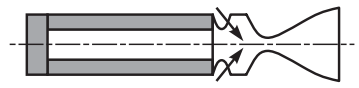

(g)

Figure 1 Typical hybrid motor concepts [1, pp. 20-152]: (a) liquid-solid reaction: head injection; $(b)$ solid feed; $(c)$ gel feed; $(d)$ gas-solid reaction: motopropellant gas generator; $(e)$ bi-propellant gas generator; $(f)$ liquid-gas reaction: aft oxidizer injection; and $(g)$ aft Venturi injection 
plication). The solid state can also be obtained either by freezing a fuel grain such as ethylene and $n$-pentane that has been tested at laboratory scale, or by gelling a liquid fuel sustained by an internal matrix. The inverse-hybrid motor concept uses a liquid fuel and an oxidizer grain; it works in the same way as the "standard" one.

Among all the design concepts mentioned before, the standard hybrid rocket (scheme of Fig. 1a) has received most attention: from its first demonstration during $30 \mathrm{~s}$ by L. Andrussow with O. Lutz and W. Noeggerarth, tested a 10kilonewton hybrid motor using coal and gaseous nitrous oxide (work done for Farben) to its use to win the X Prize. The inverse-hybrid motor, even being a subject of some studies is not a solution: industrial manufacturing of an oxidizer solid grain is not feasible with current technologies.

Aside of research works, this historical survey shows propulsion units used by students for small satellites, and some dead-ends such as the LOx/HTPB concept for ETO access examined for its potential very low cost (however, this combination highlights a series of technical problems without any performance advantage over the existing $\mathrm{LOx} /$ kerosene family). Nevertheless, if the combination of propellant is not only focused on the lowerst possible cost, hybrid motors may represent a potential breakthrough, using advanced approaches for the ETO access.

\section{HISTORICAL SURVEY AND HIGHLIGHTS}

This survey is limited to the experience obtained with in-flight tests or largemotor ground tests. For a more detailed history, the papers [2, 3] will give more information.

The early developments date back to the 1930s: to the first recorded flight of a GIRD-09 in August 1933 reported by S. Korolev and M. Tikhonravov (180 mm in diameter with $500 \mathrm{~N}$ thrust, it reached an altitude of $1500 \mathrm{~m}$ ). The propellants were gelled gasoline suspended on a metal mesh and self-pressurized LOx (refer to www.hybridracketen.de). In the mid-1940s, The Pacific Rocket Society tested a hybrid motor operating on LOx with Wax/black carbon rubber-based fuel or wood (Douglas Fir). Its most successful and the last (presennably) flight occurred in June 1951 - XDF-23 — using a rubber-based fuel reaching an altitude of about $9 \mathrm{~km}$. In the mid-1950s, General Electric, under the sponsorship of the Army Ordinance Department, ran more than 300 tests of hybrid motors on $90 \%$ hydrogen peroxide (catalytic decomposition) and PE propellants. This work demonstrated, on the one hand, easy throttling by means of a valve and stable combustion but, on the other hand, a low burning rate that could not be varied significantly and practical problems with using hydrogen peroxide caused by its inherent chemical instability. In the same period, both the Applied Physics Laboratory of the John Hopkins University, Thiokol and UTC (CSD) 
experimented with inverse-hybrid motors with various oxidizers. This solution was quickly abandoned due to running into difficulties. In the mid-1960s, UTC, sponsored by NASA, tested a hybrid motor using a FLOx (30\%/70\% mixture of Liquid Oxygen and Liquid Fluorine) associated with solid fuel made of PBAN loaded with $\mathrm{Li}$ and $\mathrm{LiH}$. This combination is hypergolic. The motor was $1.07 \mathrm{~m}$ in diameter with an eleven-port wagon-wheel grain; the specific impulse was about $380 \mathrm{~s}$ for the area ratio of 40 (Aviation Week, January 26, 1970).

Between 1960 and 1980, the U.S. developed target drones with two levels of thrust:

- the Sandpiper conceived by UTC, using MON 25 and PMMA/Mg fuel $(10 \% \mathrm{Mg})$, the first flight of the 6-flight compaign occurred in January 1968 (combustion duration $300 \mathrm{~s}$, throttling ratio 8/1, horizontal flight up to $160 \mathrm{~km}$, launched from an aircraft);

- the High Altitude Supersonic Target (HAST) using IRFNA fed by a turbopump and PMMA/PB (20\%/80\%) fuel in a stacked-cruciform grain (38 samples), thrust modulation was in a ratio of 10/1. While the Sandpiper was expandable, the HAST was recovered after flight, it used a CSD motor; and

- the Firebolt Target (with 40 samples) under development by Teledyne Ryan, manufactured by Beach Aircraft, was a later version with a motor similar to the HAST. The Firebolt completed its evaluation period in 1984; however, no production contract was ever given.

After 1995, there were two significant sounding rocket programs in the USA: ( $i$ ) the Hyperion using $\mathrm{N}_{2} \mathrm{O}$ and HTPB (4 flights, the last in 1997); and (ii) Lockheed Martin flew in 2002, a larger one using LOx/HTPB with an initial thrust of $267 \mathrm{kN}$.

In Europe, ONERA developed the LEX sounding rocket with 8 successful flights between 1964 and 1967 - MON (Nitrous Oxide) 40/NMTD (Metatoluene Diamine Nylon) — reaching an altitude in excess of $100 \mathrm{~km}$ and then with SEP (Snecma today) and Nord Aviation (Astrium Space Transportation today) the biggest version - SPAL 30 - for a drone (no in-flight tests). The formulations have shown a relatively high burning rate and the propulsion system - a very good overall efficiency. In Sweden, Volvo tested (1965) in-flight 2 HR-3 sounding rockets (IRFNA and $\mathrm{PB}$ /aromatic amines) with the formulation very close to those of ONERA [4]. More recently, Nammo Raufoss conducted the static firing of their first full-scale hybrid motor, a part of the Norwegian Sounding Rocket (NSR) (30 kN thrust, $200 \mathrm{~kg}$ of LOx). This development was led in cooperation with Lockheed Martin (LM) Michoud Operations, New Orleans, USA. The largescale hybrid motors were tested only in the USA. First tests were made by UTC with the HTM-series motors in the 1960s under the U.S. Air Force funding. The propellants were $\mathrm{N}_{2} \mathrm{O}_{4}$ as the oxidizer and aluminized $\mathrm{PB}$ as the fuel (motor 


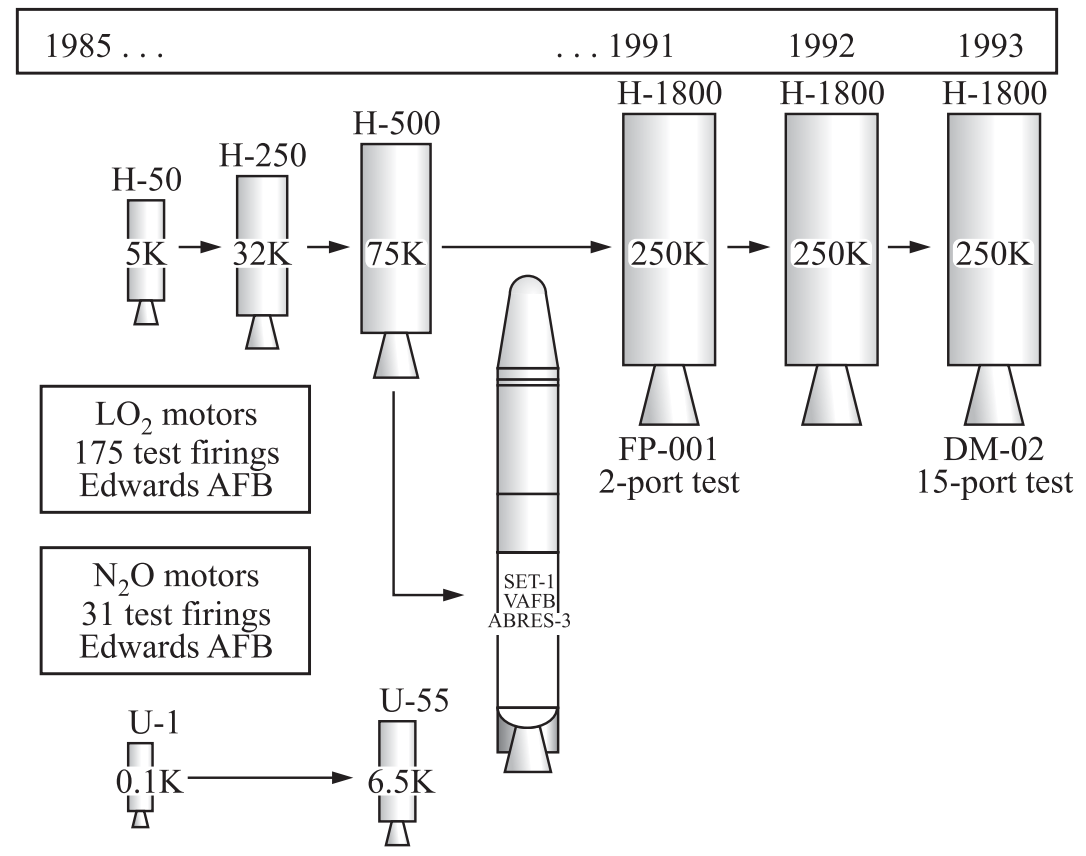

Figure 2 AMROC test history [3]

$97 \mathrm{~cm}$ in diameter and $180 \mathrm{kN}$ thrust). In 1981, the Starstruck company was created to develop a large sounding rocket, The Dolphin, using LOx/PB and weighting about 8 t. After 6 ground tests, a flight test was a failure (1984). The company was reorganized and named AMROC, which was an entirely private funded company. In the period from 1985 to 1993, 139 motors of different size were built and 240 firings were performed, mainly with LOx/HTPB, between 20 and $1100 \mathrm{kN}$ thrust. In 1989, flight failure occurred with a SET-1 rocket. A stuck valve frozen due to humidity prevented the reaching of the thrust and after shutdown an external fire damaged the rocket in such a way that another launch became impossible (Fig. 2).

In 1990-1993, AMROC carried mainly the design of Aquila, a small launch vehicle (900 kg to a LEO). This development was based on the $\mathrm{H}-250 \mathrm{~K}$, a hybrid LOx/PB motor of $1000 \mathrm{kN}$ thrust. The Hybrid Technology Option Project (HyTOP) including AMROC, CSD, and Martin Marietta took the relay (large motors tested in 1993 and 1994 with low-frequency instability problems) to demonstrate the low cost development of hybrid propulsion. In 1995, AMROC lost its sponsors, and as the cost to solve the problems was too high, it ceased activities. AMROC was bought by the SpaceDev society in 1998. Nevertheless, a new program, Hybrid Demonstration Program (HPDP), with Thiokol replac- 
ing AMROC was initiated. The propellant formulations were still based on LOx/HTPB with wagon-wheel geometry grains. Four tests of a 1.1-meganewton thrust motor were performed with a lot of combustion issues. AMROC, even though it was not successful, has demonstrated the capacity of hybrid motors to be extinguished and reignited, as well as safety and nonexplosive nature of operation. In summary, more than 15 years from the mid-1980s to the early 2000s were spent for the development of large hybrid motors by three organizations, namely, Starstruck, AMROC, and the consortium mentioned above. All these programs were based on the LOx/HTPB propellants because of cost, good physical properties, and performances. The major problem encountered by all these groups was combustion stability when scaled to a larger size [5].

Within the Lockheed Martin HYSR Project, a large-scale hybrid rocket was successfully launched from the NASA WFF on December 18, 2002 as a technology demonstration for hybrid propulsion and related subsystems. The HYSR Program started in 1999. The overall goal of the program was to develop a single-stage propulsion system capable of replacing existing two- and three-stage sounding rockets. The hybrid rocket had a propellant combination of LOx and HTPB and produced approximately $60.000 \mathrm{lb}$ of vacuum thrust. The three-year technology demonstration program was a collaborative effort between NASA and Lockheed Martin.

Scaled Composites Space Ship One, the Ansari X Prize winner, was a contest with a $\$ 10$ million reward for the first commercial company to get 3 people to 62 nautical miles altitude and repeat within 2 weeks a two-stage Composites built airplane to win the prize with the hybrid rocket powered by an $\mathrm{N}_{2} \mathrm{O} / \mathrm{HTPB}$ with a 80 -second maximum burn time. Nitrous oxide, $\mathrm{N}_{2} \mathrm{O}$, was self-pressurized. The in-flight use of an $\mathrm{N}_{2} \mathrm{O} / \mathrm{HTPB}$ motor by Rutan on the Space Ship One to win the $\mathrm{X}$ Prize closed happily the U.S. hybrid motor history (even despite it experienced some combustion instabilities). The history will continue with a larger vehicle the Space Ship 2 (Fig. 3).

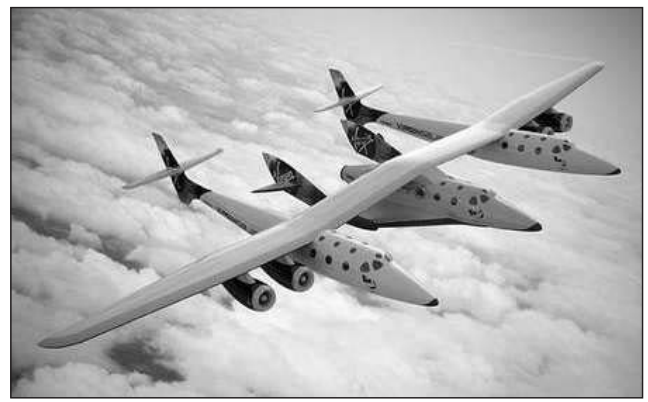

Figure 3 Spaceship 2 overview (courtesy: Virgin Galactic) 


\section{ADVANTAGES OF HYBRID PROPULSION}

Hybrid propulsion is not a mature technology for large boosters. This technology requires the cooperation of two different engineering technologies - solid and liquid propulsion that are not used to work together. Due to its characteristics (i.e., separately stored fuel and oxidizer), hybrid propulsion systems may offer important advantages over their liquid and solid competitors. The following advantages for the classical hybrid motors are commonly recognized in the propulsion community and their relevance will be discussed:

- higher performances than those of liquid and solid rockets;

- very safe fabrication, storage, and testing;

- better operability at a lower cost;

- minimal environmental impact;

- much lower propulsion system cost;

- high reliability (half pumps and plumbing of a liquid propulsion system; an insensitive solid-propellant grain tolerant to cracks);

- stop-start-restart capabilities; and

- controllable thrust shaping on demand.

\subsection{Propulsion Performance}

The performance of a propulsion system has to be evaluated doing comparative stages designs. Nevertheless, several parameters are useful to have the first idea for comparing propellants: theoretical specific impulse; combustion efficiency, a useful system parameter indicating the practical specific impulse; reasonable throat erosion; equivalent density (this parameter is of first importance when a hybrid system has to replace an existing system with layout constraints); and amount of residuals.

\subsubsection{Theoretical performance}

Table 1 shows the performance capabilities of several fuel/oxidizer couples [3]. Table 2 shows the comparative performances of one of the most studied couples of hybrid propellants - LOx/HTPB - with conventional solid and liquid formulations. The hybrid couple is potentially better than solids and better than storable bipropellants and competitive with semistorable propellants. A fair comparison has to be made through a comparative global analysis for a given 
Table 1 Performances capability for several fuel/oxidizer couples [3] $\left(P_{c}\right.$ $=3.5 \mathrm{MPa}$ and $P_{e}=0.1 \mathrm{MPa}$ (sea level))

\begin{tabular}{|c|c|c|c|c|}
\hline \multicolumn{5}{|c|}{ Performance of hybrid propellants } \\
\hline Fuel & Oxidizer & Optimum O/F & $I_{\mathrm{sp}}, \mathrm{s}$ & $c^{*}, \mathrm{~m} / \mathrm{s}$ \\
\hline HTPB & $\mathrm{LOx}$ & 1.9 & 280 & 1820 \\
\hline $\operatorname{PMM}\left(\mathrm{C}_{5} \mathrm{H}_{8} \mathrm{O}_{2}\right)$ & LOx & 1.5 & 259 & 1661 \\
\hline НTPB & $\mathrm{N}_{2} \mathrm{O}$ & 7.1 & 247 & 1604 \\
\hline НТРВ & $\mathrm{N}_{2} \mathrm{O}_{4}$ & 3.5 & 258 & 1663 \\
\hline НTPB & RFNA & 4.3 & 247 & 1591 \\
\hline НТРВ & $\mathrm{FLOx}\left(\mathrm{OF}_{2}\right)$ & 3.3 & 314 & 2042 \\
\hline $\mathrm{Li} / \mathrm{LiH} / \mathrm{HTPB}$ & $\mathrm{FLOx}\left(\mathrm{OF}_{2}\right)$ & 2.8 & 326 & 2118 \\
\hline $\mathrm{PE}$ & $\mathrm{LOx}$ & 2.5 & 279 & 1791 \\
\hline $\mathrm{PE}$ & $\mathrm{N}_{2} \mathrm{O}$ & 8 & 247 & 1600 \\
\hline Paraffin & LOx & 2.5 & 281 & 1804 \\
\hline Paraffin & $\mathrm{N}_{2} \mathrm{O}$ & 8 & 248 & 1606 \\
\hline Paraffin & $\mathrm{N}_{2} \mathrm{O}_{4}$ & 4 & 248 & 1667 \\
\hline $\mathrm{HTPB} / \mathrm{Al}(40 \%)$ & $\mathrm{LOx}$ & 1.1 & 274 & 1757 \\
\hline $\mathrm{HTPB} / \mathrm{Al}(40 \%)$ & $\mathrm{N}_{2} \mathrm{O}$ & 3.5 & 252 & 1637 \\
\hline $\mathrm{HTPB} / \mathrm{Al}(40 \%)$ & $\mathrm{N}_{2} \mathrm{O}_{4}$ & 1.7 & 261 & 1679 \\
\hline $\mathrm{HTPB} / \mathrm{Al}(60 \%)$ & $\mathrm{FLOx}\left(\mathrm{OF}_{2}\right)$ & 2.5 & 312 & 2006 \\
\hline Cellulose $\left(\mathrm{C}_{6} \mathrm{H}_{10} \mathrm{O}_{5}\right)$ & GOx & 1 & 247 & 1572 \\
\hline Carbon & Air & 11.3 & 184 & 1224 \\
\hline Carbon & $\mathrm{LOx}$ & 1.9 & 249 & 1599 \\
\hline Carbon & $\mathrm{N}_{2} \mathrm{O}$ & 6.3 & 236 & 1522 \\
\hline \multicolumn{5}{|c|}{ Cryogenic hybrids } \\
\hline Pentane (s) & $\mathrm{LOx}$ & 2.7 & 279 & 1789 \\
\hline $\mathrm{CH}_{4}(\mathrm{~s})$ & $\mathrm{LOx}$ & 3 & 291 & 1871 \\
\hline $\mathrm{CH}_{4}(\mathrm{~s}) / \mathrm{Be}(36 \%)$ & $\mathrm{LOx}$ & 1.3 & 306 & 1918 \\
\hline $\mathrm{NH}_{3}(\mathrm{~s}) / \mathrm{Be}(36 \%)$ & $\mathrm{LOx}$ & 0.47 & 307 & 1967 \\
\hline \multicolumn{5}{|c|}{ Reverse hybrids } \\
\hline JP-4 & $\mathrm{AN}$ & 17 & 216 & 1418 \\
\hline JP-4 & $\mathrm{AP}$ & 9.1 & 235 & 1526 \\
\hline JP-4 & NP & 3.6 & 259 & 1669 \\
\hline
\end{tabular}

Note: JP-4 is kerosene and nearly all of these combinations in the table have been tested at least at laboratory scale.

mission. Less dense than solid, a hybrid stage is more cumbersome but amazingly could be lighter than a solid solution. The higher $I_{\mathrm{Sv}}$ largely gives the advantage over solid formulations and also over NTO/MMH. The competition between $\mathrm{LOx} /$ kerosene or LOx/methane with LOx/HTPB or PE (all "green propellants") is questionable: the specific impulse is not better and the high level of residuals handicaps this hybrid solution (Fig. 4). As for the specific impulse, better combinations exist that will be examined later; nevertheless, no classical fuel (i. e., PE, Wax, Nylon/MNTD) associated with a better potential oxidizer in 
Table 2 Theoretical $I_{\mathrm{sv}}$ : comparison between current propellant and LOx/HTPB [6]

\begin{tabular}{lcccc}
\hline \multirow{2}{*}{ Propellant } & Mixture ratio & $\begin{array}{c}\text { Equivalent } \\
\text { density, } \\
\mathrm{kg} / \mathrm{m}^{3}\end{array}$ & $\begin{array}{c}I_{\text {sv th }} \\
\left(P_{c}=7 \mathrm{MPa}, \Sigma=40\right)\end{array}$ \\
\hline Solid & $\mathrm{AP} / \mathrm{HTPB} / \mathrm{Al}$ & $68 / 18 / 14$ & 1750 & 315 \\
\hline Hybrid & $\mathrm{LOx} / \mathrm{HTPB}$ & $72 / 28$ & 1060 & 354 \\
\hline Liquid & $\mathrm{NTO} / \mathrm{MMH}$ & 2.37 & 1200 & 341 \\
\hline \multirow{5}{*}{ Bipropellants } & $\mathrm{H}_{2} \mathrm{O}_{2} / \mathrm{RP} 1$ & 7.0 & 1320 & 314 \\
& $\mathrm{LOx} / \mathrm{RP} 1$ & 2.77 & 1030 & 358 \\
& $\mathrm{LOx} / \mathrm{CH}_{4}$ & 3.45 & 830 & 369 \\
& $\mathrm{LOx} / \mathrm{LH}_{2}$ & 4.8 & 320 & 455 \\
\hline
\end{tabular}

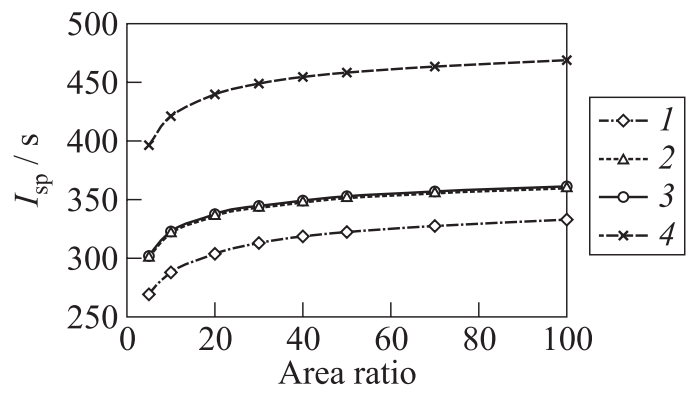

Figure 4 Theoretical specific impulse: comparison between $\operatorname{HTPB}(1)$, HTPB/LOx (2), LOx/RPI (3), and $\mathrm{LO}_{2} / \mathrm{LH}_{2}$ (4) vs. area ratio [7]

competition is able to deliver a much higher $I_{\mathrm{sv}}$ than LOx/methane propellant formulation.

\subsubsection{Combustion efficiency}

Hybrid propellants burn differently from both liquid and solid propellants. For the classical HTPB hybrid propellant, mixing and combustion occur in a diffusion flame zone that is in the same range of length as the inner bore. A very strong research effort has been made on this subject. Risha from Penn State University [3] mentioned $C^{*}$ efficiencies in the range of $72 \%-91 \%$.

Several measures could be undertaken (separately or combined) to have a reasonable or even good efficiency level: special grain design; special oxidizer injection techniques; and improved fuel grain formulation.

The special grain design aiming at creating and organizing turbulent zones (all along the inner bore) will play a dual role: $(i)$ increasing combustion ef- 
ficiency; and $(i i)$ lowering the risk of combustion instabilities (medium frequency $=$ acoustic coupling).

A widely proposed solution is to create a premixing chamber and a postcombustion chamber, including or not secondary injection of oxidizer; all the AMROC stages for Aquila and HyFLYER, and the LEX of ONERA were designed with these chambers. Another way could be to have distributed slots [8] or a central cavity (on very long solid grains; the ASSM-POP Cnes program showed the advantages of this solution by tests and computations for solid propellants; however, for hybrid propellants, the efficiency of these solutions has yet to be demonstrated). Another solution is to include turbulence generators like metal or plastic screens in the fuel grain so that after regression the obstacles are created all along the inner channel [9] (localized turbulence), or to include crystalline loads increasing surface roughness in the course of gasification (ejected distributed turbulence).

\subsubsection{Injection systems}

In the early developed hybrid motors in France (Sounding Rocket LEX, SPAL30 for the C30.C Target Drone), ONERA paid particular attention to the injection system to avoid losing room with large premixing and postcombustion chambers. The injection design resulted from extensive experimental work and led to specific impulse efficiencies greater than 0.95 [4]. If taking into account the $C_{F}$ effects, this means very high efficiency with $C^{*}$ values in the range of those for liquid propellant (0.99 for the acceleration regime). The basis of this design was to completely eliminate laminar combustion and have premixed turbulent combustion from the very beginning.

The combustion chamber was divided into two parts, the first one ended by an elastomeric diaphragm. The first chamber injector consisted of 6 tubes / 30 vortex injectors (injector A). The diaphragm injector consisted of 108 elementary vortex injectors (injectors B and C). The main grain was a 6-branch star with a MON 40 / NMTD combination (Fig. 5). This combination is not hypergolic. Self-ignition was obtained with the ignition liner made of Paraphenylene Diamine (8 successful LEX flights, 3 SPAL 30 ground tests, configuration with 3 channels and 16-kilonewton thrust). The measured specific impulse efficiency was of 0.95 taking into account $C_{F}$ losses. This means that it is possible to have $C^{*}$ combustion efficiencies at the level of liquid propellants. From this period, vortex injection became a subject of many experimental studies and modeling works (see, e.g., Majdalani [3]), and patents (see, e.g., AMROC U.S. Patent 5794435).

A more classical injector head was used by AMROC with LOx/HTPB combustion such as that described in the U.S. Patent 5794435. Also, a classical shower-head with or without diverging jets should be mentioned (Fig. 6). The configuration of Fig. $6 a$ led to stable combustion due to strong recirculation 


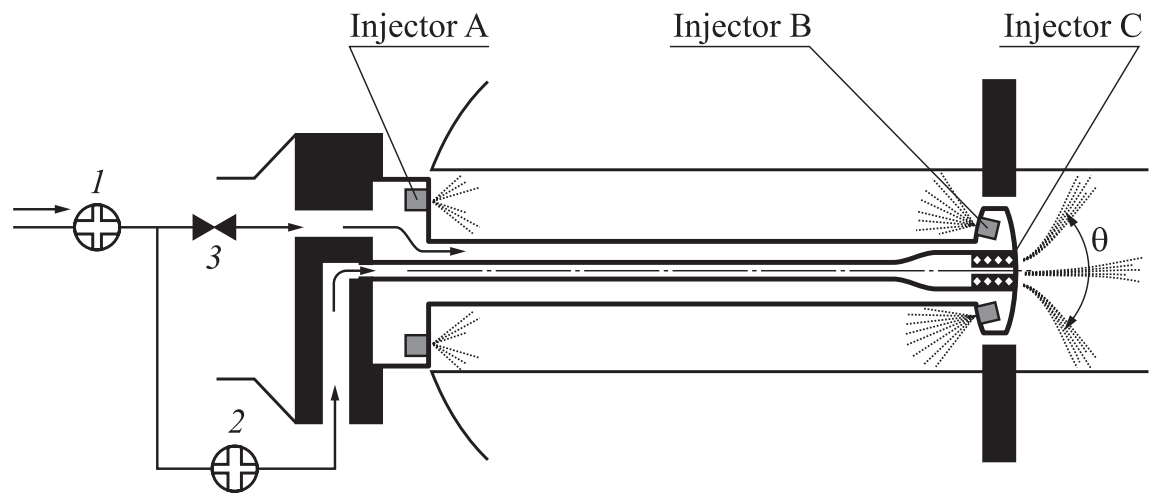

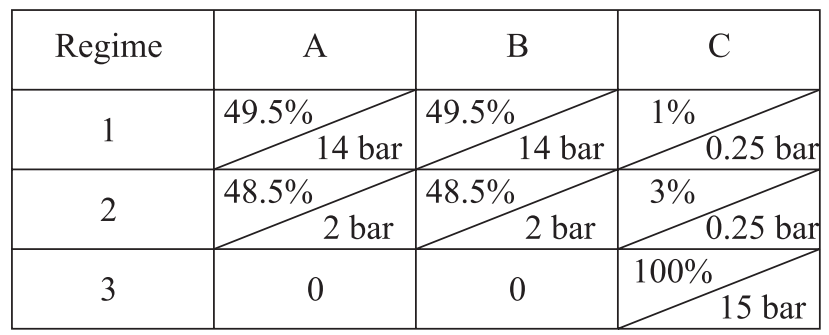

Figure 5 SPAL motor injection device: 1 - main valve; 2 - calibrated orifice; and 3 - by-pass valve

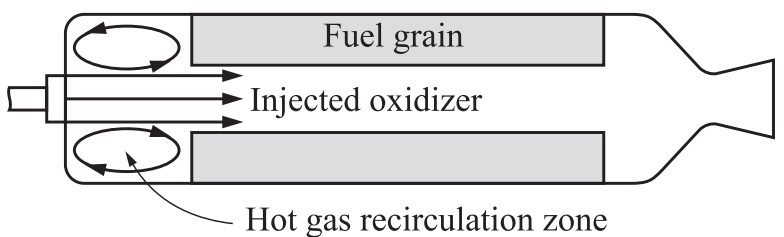

(a)

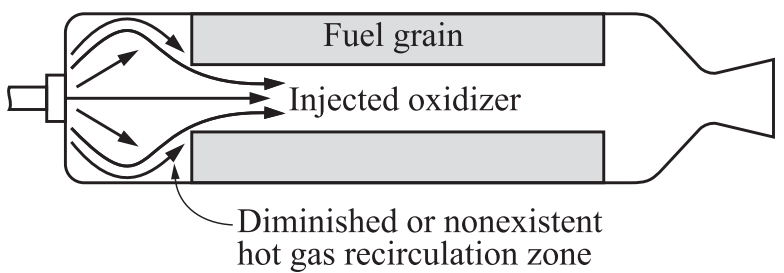

(b)

Figure 6 Classical shower-head without $(a)$ and with $(b)$ diverging jets 
whereas the configuration of Fig. $6 b$ was not that stable. This kind of injector is associated with a premixing chamber [3, 11]; nevertheless, it was probably not so simple. In fact, AMROC added a finocyl grain and a deflector in the premixing chamber: the fins and flow deflector were designed to promote flame holding in combustion ports. Here, the $C^{*}$-efficiency could reach 0.98 without combustion instabilities. In conclusion to this point, it is possible playing on several parameters to reach a good efficiency without combustion instabilities, the counterpart being either a more cumbersome motor or a more sophisticated design.

\subsubsection{Throat material erosion rate}

The nozzle of a hybrid motor uses the same technologies as those used for solid motors (Table 3). The exhaust gases are very chemically aggressive for throat materials. Therefore, one has to take into account that the same combustion pressure requires a lower average area ratio which results in a lower average specific impulse.

Some advanced hybrid propellants (including hydrides) whose exhaust gas composition is close to that of solid propellants, will exhibit a much better behavior and will not show significant differences with the solids. The effluents of

Table 3 Comparison of erosivity [10]

\begin{tabular}{lcc}
\hline \multirow{2}{*}{ Throat materials } & \multicolumn{2}{c}{ Erosivity, mm/s } \\
\cline { 2 - 3 } & Solid (HTPB) & Classical hybrid \\
\hline Carbon/phenolic resin & 0.252 & 0.65 \\
Silica/phenolic resin & 0.42 & 1.12 \\
Carbon/carbon & 0.13 & 0.24 \\
\hline
\end{tabular}

Table 4 Combustion gas composition (moles/100 g)

\begin{tabular}{lcccc}
\hline Composition & $\mathrm{LOx}_{-} \mathrm{CH}_{4}$ & Solid & Wax & Wax $\mathrm{MgH}_{2}$ \\
\hline $\mathrm{H}$ & 0.161 & 0.156 & 0.035 & 0.016 \\
$\mathrm{H}_{2}$ & 0.398 & 1.136 & 0.074 & 2.955 \\
$\mathrm{OH}$ & 0.359 & 0.024 & 0.278 & 0.000 \\
\hline $\mathrm{H}_{2} \mathrm{O}$ & 2.112 & 0.035 & 1.255 & 0.005 \\
$\mathrm{O}$ & 0.085 & 0.002 & 0.076 & \\
\hline $\mathrm{O}_{2}$ & 0.178 & 0.000 & 0.506 & \\
$\mathrm{CO}$ & 0.824 & 0.847 & 0.455 & 1.404 \\
\hline $\mathrm{CO}_{2}$ & 0.562 & 0.032 & 0.961 & 0.000 \\
$\mathrm{~N}_{2}$ & & 0.288 & & \\
\hline $\mathrm{AL}_{2} \mathrm{O}_{3}$ & & 0.337 & & \\
$\mathrm{HCl}_{\mathrm{MGO}}$ & & 0.467 & & \\
\hline & & & & 1.090 \\
\hline
\end{tabular}


typical hybrid propellants (excluding afterburning in the exhaust plume) could have very low erosivity: a potential low cost formulation $\left(\mathrm{LOx} / \mathrm{Wax} / \mathrm{MgH}_{2}\right)$ will show lower erosivity than a classical solid formulation (Table 4) with its large amount of hydrogen and without water and $\mathrm{CO}_{2}$.

\subsubsection{Equivalent density effect}

Without any constraints of layout, the effect of lower bulk density as compared to solid-propellant density may only be evaluated by a complete design of a stage; the launch vehicle for the same payload will be bigger but with a lower liftoff mass [12]. For example, the replacement of the shuttle booster by conventional $\mathrm{LOx} / \mathrm{HTPB}$ would require $59 \mathrm{t}$ less propellant but with an increased diameter from 150 in $(3.81 \mathrm{~m})$ to $180 \mathrm{in}(4.57 \mathrm{~m})$ with an increased length of more than $5 \mathrm{~m}$. It is equivalent in size and propellant mass with an LOx/RP1 booster. Classical hybrid propellants, when studied to replace a solid propellant with layout constraints, need an improved solution (more energetic fuel) to be really competitive (example of the MPS Ariane 5 replacement [8] where, with the layout constraints (launch-pad, and Ariane itself), only a maximum of $2 \times 210 \mathrm{t}$ can be loaded but may potentially increase the performance of the launch vehicle of $2 \mathrm{t}$ with the use of an improved Alane Hybrid).

\subsubsection{Residuals}

Solid propellants have a negligible amount of residuals and liquids of less than $2 \%$. Classical hybrid propellants with a low regression rate associated to wagonwheel geometry will have a much greater level of residuals and the regression of the surface will be not regular. Moreover, stopping the engine upon full fuel consumption will be a hazardous procedure. Mainly for multiports, the amount of residuals in hybrid motors is very important: the LEX with its single-star central port had a level of residuals less than 5\%. The 1100-kilonewton AMROC motor (see Figs. 5 and 6 ) had a high level of residuals $(>15 \%)$. To obtain a very low and reproducible level of residuals on a multiple ports will be a hard point. On the one hand, the mass of residuals has to be considered as a dead mass penalizing the performance of a hybrid motor. On the other hand, if hybrid propellants with a high regression rate exist, then with a single port geometry, efficient internal insulation and low erosive formulation, the amount of residuals may be very low.

\subsection{Fabrication, Storage, and Testing}

As for handling, virtually, all hybrid fuels are considered inert (exhibit zero TNT equivalency), i. e., they can be transported using normal shipping techniques with no additional safety requirements. This is a significant benefit when compared to traditional solid propellants, where any processing is considered as 
a hazardous operation and special handling considerations must be observed. As for fabrication, manufacturing an inert grain is a major parameter affecting the production cost due to a lower safety cost. Classical hybrid motors can be cast in light industrial facilities using the techniques of traditional solid propellant casting.

For relatively small motors (with a solid grain lighter than about $10 \mathrm{t}$ ), the composite case can be directly wound on the grain (the grain itself replacing the sand mandrel used to wind with the solids). Hybrid rockets are much less sensitive to cracks and imperfections in the solid-fuel grain. Even though the oxidizer and combustion product gases can penetrate into crack cavities, reactions in the cavity regions are limited and unable to generate any significant local pressurization and grain damage.

The level of safety is increased: "In liquid bipropellant systems, leakage of propellants or structural failures due to mishandling or excess loads, whether on the launch pad or in flight, could lead to a catastrophic conflagration if the leakage or failure results in a fuel/air fire or mixing of the fuel and oxidizer. On the contrary, there is much lower probability for any violent energy release hazard involved in the event of leakage or structural failure in the hybrid's liquid oxidizer system. These safety features represent the most desirable characteristics of hybrid rockets. Their safety characteristics will definitely have a strong impact for reducing future propulsion hazards to the payload of unmanned missions, launch facilities, and manned flights" [3].

So, when looking for advanced hybrid fuels, solutions as to include some AP or to replace HTPB by an energetic binder for increasing the regression rate have to be avoided, the propellant losing partly the benefits of its low cost and its safety characteristics.

\subsection{Operability and Reliability}

Compared to liquid rockets, the relative simplicity of hybrid rockets offers important benefits in prelaunch operations due to their fewer components and operational steps. The prelaunch operations when the vehicle is fueled could be shortened, the number of controls decreasing dramatically to become closer to those for solid motors (some weeks less of launch campaign). Hybrid rockets are more complex than solid due to the need for an oxidizer delivery system, with an associated oxidizer tank pressurization system and pump if necessary. Although hybrid motors are more complex than solid, they use only one fluid system, which makes them less complex than bi-liquid systems (liquid propellant rocket engines).

\subsection{Cost}

The handling and casting process costs should be significantly lower than those for solid fuels. Since there is only one liquid (oxidizer) used, the system costs 
should be significantly lower than those for a liquid system. When dealing with advanced hybrid propellants, the use of a toxic or hazardous additive has to be proscribed being the origin of a cost increase.

\subsection{Minimal Environmental Impact + Nontoxicity $=$ "Green" propellant}

LOx/RP1 or other "classical" hybrid fuels are comparable with "green" liquids: the exhaust gases contain neither hydrochloric acid nor alumina: there is no risk of local pollution by acid rain or alumina or toxic products. Thus, it is a solution reducing the pollution to a minimum. Rocket launchers are identified to have four types of effects on the atmosphere, including stratospheric ozone depletion, acid rain, reduction of local air quality due to dispersion of toxic compounds, and global warming. The effect of solid and liquid propellants on ozone depletion is a very controversial subject. The following major points may be noticed:

- with the current number of flights per year, this effect is completely negligible [13] in comparison with other human activities and natural sources. In a long-term perspective and regulatory demand to reduce the pollution to a minimum, the classical solution is a good answer vs. storable propellants or solids; and

- advanced hybrid propellants have to comply with these requirements; it means that some additives such as beryllium whose oxide is a highly toxic species will be prohibited.

\subsection{Stop-Start-Restart Capabilities}

The most important point is the possibility to stop a motor that may solve many safety problems. For example, in the hybrid project for the Shuttle, this is the only solution to save and recover the astronauts during the boost phase (need to stop the propulsion before astronauts ejection); in a conventional launch vehicle, it is the only solution with liquids to be able to respect the safety zones. The stop-restart capabilities is mainly required for upper stages and results in launch vehicle optimization in terms of cost and performances. For example, in a GEO mission, the Ariane Upper Stage has to deliver several separated impulses, the first two are interrupted by a ballistic phase resulting from trajectory optimization, whereas the last one is needed to clean the orbit. Generally speaking, the design of a two-stage launch vehicle (low-cost architecture) includes a capability of restart for the upper stage. The trajectory of Vega includes ballistic phases and it will be very beneficial to replace the Z9 upper stage and the Avum by a single hybrid upper stage [14]. This advantage over solid motor is also highly appreciated when designing small launch vehicles where solid fuels are generally the best answer in terms of cost efficiency. 


\section{7 $\quad$ Throttling Capabilities}

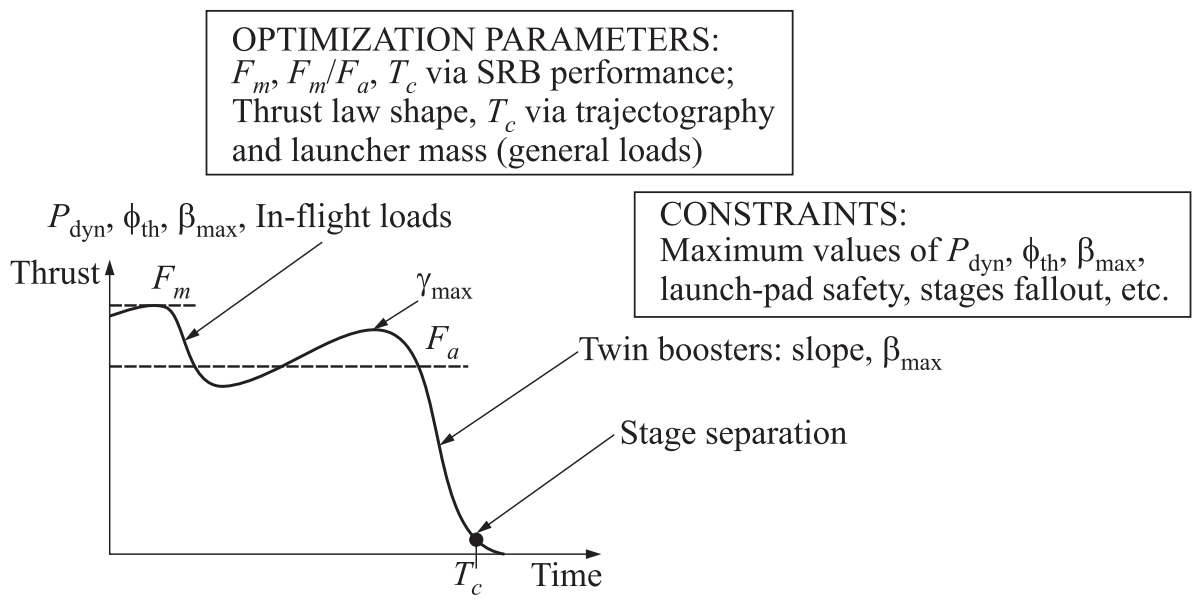

Figure 7 Thrust law shape optimization and design criteria [15]

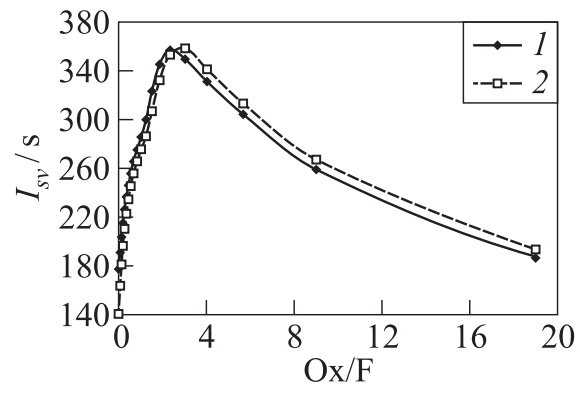

Figure 8 Specific impulse vs. oxidizer-tofuel ratio $(7 \mathrm{MPa}, E=40): 1-\mathrm{HTPB}$; and $2-$ Wax
Many researchers emphasize the flexibility given by the throttling capabilities of hybrid motors. This feature allows tailoring the shutdown and obtaining an accurate delivered velocity increment $(D V)$ and, therefore, an accurate position, as the liquid engines are able to do. From a system point of view, a versatile tailoring is of the first interest for some military applications. For a civilian launch vehicle, to shape the thrust law is only important for the boosters; as Ariane 5 designed for a given mission, so, this shape, once defined an optimized, is always the same (Fig. 7).

This throttling capability of hybrid propulsion is virtually not a real advantage over solid motors where the thrust can be tailored as required without losses in specific impulse. For a solid motor, the mixture ratio is invariant by nature. For hybrid motors with a constant oxidizer mass flow rate, the thrust will decrease and the mixture ratio increase leading as counterpart to an average specific impulse loss that will depend on the motor design (Fig. 8). 
Nevertheless, with long grain and oxidizer flow regulation (to stay at the maximum specific impulse), the thrust law shape is naturally decreasing, that is a better compromise than a liquid engine with constant thrust.

\section{CHALLENGES IN HYBRID PROPULSION}

Hybrid propulsion could clearly be of interest. So, the question is: why it was never fully developed for large boosters for an ETO use. As compared to liquid propulsion, the specific impulses of classical hybrid propulsion are not better. Developing and creating a new propulsion family is costly in terms of financial and human investments; the propulsion industries are sharply divided with their experience in liquid or solid motors. This technology does not take any benefit of military involvements: solid propellant propulsion is currently quite the only technology used (even for very special systems, battleships, generally, forbid the use of liquid propellants).

More important are technical problems. The regression rate is really too low, it results in a complex design of the solid part with a multiport grain, difficulties in combustion control (the regression rate depends on many parameters) and, in a great amount of residuals which may handicap hybrid propulsion. The challenge is to find a new fuel with a regression rate higher by a factor of minimum 5 than that of LOx/HTPB combustion to allow a single-port grain as in solid motors. The specific impulse level has to be better than that for the liquids (except for $\mathrm{LOx} / \mathrm{LH}_{2}$ ), giving to this kind of propulsion a definite advantage both over solid and liquid counterparts whatever the application could be. Nevertheless, the objective to obtain the same level as that of $\mathrm{LOx} /$ methane or to be a little better in terms of $I_{\mathrm{sv}}$ could be an interesting objective if a target of very low cost can be reached without any technical problem.

\section{NEW ENERGETIC HYBRIDS}

What could be an improved hybrid fuel? The choice of the oxidizer seems obvious: it should be more energetic, high density, nontoxic, cheap to produce with a capacity of self-pressurization and eventually nozzle cooling. It is liquid oxygen. For application or mission asking a long-term storage in space or an easier handling, hydrogen peroxide and MON are the best candidates. The major problem is to select a new fuel with the two major objectives: $(i)$ increase significantly the regression rate; $(i i)$ attain a higher specific impulse, or both, without losing any specific advantages of hybrids. So, the solid grain has to be constituted of the combination of a basic polymer, a fuel (no oxidizer at all), and an additive (metal or hydride). The formulation used on the LEX could 
be taken as a reference (Nylon/Metatoluene Diamine with a regression rate between 3.5 and $5 \mathrm{~mm} / \mathrm{s}$ ). Note, the literature reports about many tests made at low pressure; therefore, some laboratory results on the regression rate may be not relevant. In a modern motor, the combustion pressure will be in the range from 6 to $10 \mathrm{MPa}$.

\subsection{Choice of Basic Polymer or Fuel}

For many years, HTPB was a likely candidate for hybrid motors for ETO applications. The overall reaction with oxygen is taken as [16]:

$$
\mathrm{C}_{4} \mathrm{H}_{6}+\frac{11}{2} \mathrm{O}_{2} \rightarrow 3 \mathrm{H}_{2} \mathrm{O}_{2}+4 \mathrm{CO}_{2}+6.8 \mathrm{kcal} / \mathrm{g} .
$$

HTPB has a high endothermic heat of ablation, the pyrolised fuel vapor is transported to the flame zone by convection and diffusion, where it mixes with the oxidizer and burns, but the fuel flux due to the pyrolisis blocks some of the heat transfer to the surface which is the cause of a low regression rate [3]. Moreover, if looking for the way to incorporate additives, some hydrides may react with the isocyanates (USP 2003/0164215, September 4, 2003) used for HTPB manufacturing. Therefore, other binders have to be considered, e.g., an energetic binder such as the GAP possessing a low heat of ablation (70 vs. $800 \mathrm{cal} / \mathrm{g}$ for PE and HTPB). The regression law of GAP is different, it possesses an autonomous burning rate which may reach 15 instead of $1 \mathrm{~mm} / \mathrm{s}$ and may be envisaged as a ballistic additive aimed at keeping the self-extinction capacity of solid fuel. Dicyclopentadiene (DCPD) polymer was a subject of studies because it has the useful attributes of being hydrophobic and capable of encapsulating reactive fuels such as $\mathrm{LIAlH}_{4}(\mathrm{LAH})$ [3, p. 478].

Wax used in hybrid fuels is a mixture of $n$-alkanes (nonpolymeric saturated hydrocarbons) and similar to DCPD or PE does not contain oxygen. It is well capable of encapsulating reactive loading, with a better carbon/hydrogen ratio. Its performance associated to LOx is better than that of DCPD and equivalent to that of HTPB. Thus, Wax could be an ideal candidate to replace HTPB. The major advantage of HTPB is its basic regression rate (without any additive) which is greater by a factor of $2.5-3.5$ [3, p. 93]. The choice will not be done based on the criterion of high $I_{\mathrm{sv}}$ rather on the criteria of safety, combustion properties, and compatibility with solid reactive fuels or additives.

\subsection{Choice of Additive}

\subsubsection{Effect of additives on performance}

From the stand point of performances, Fig. 9 compares some additives often studied at small-scale levels. This figure indicates that if aluminum is stud- 


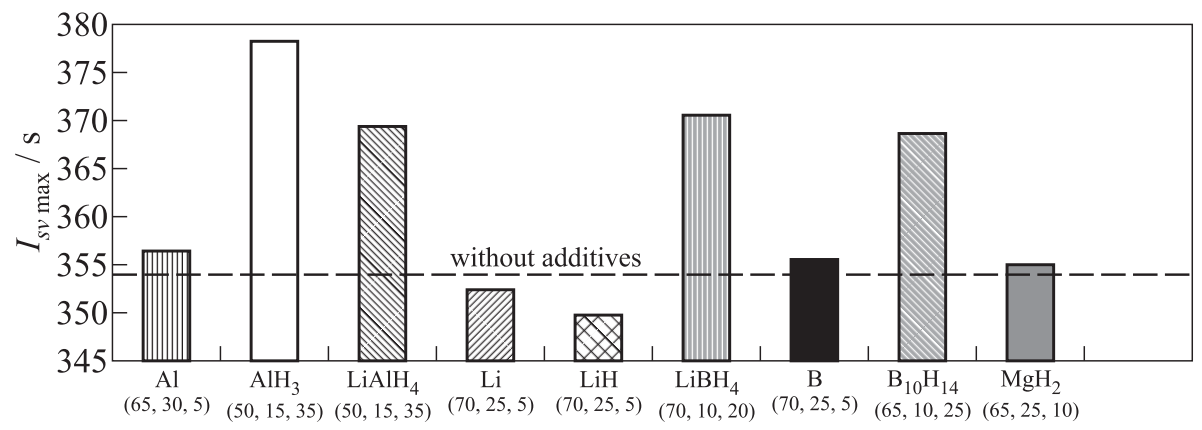

LOx/HTPB additives

Figure 9 The SNPE computations (reference LOx/HTPB: 357 s, LOx/Wax: 359 s)

ied, it is not for its effect on the specific impulse that is lower than for a pure $\mathrm{LOx} / \mathrm{HTPB}$ combination. Boron and magnesium hydride are also not better. Lithium $\mathrm{Li}$ and $\mathrm{LiH}$ give a lower performance. Alane $\left(\mathrm{ALH}_{3}\right), \mathrm{LAH}\left(\mathrm{LiALH}_{4}\right)$, $\mathrm{LiBH}_{4}, \mathrm{~B}_{10} \mathrm{H}_{4}$ and magnesium borohydride $\mathrm{Mg}\left(\mathrm{BH}_{4}\right)_{2}$ are good candidates. The effect on the global density is also always positive, these additive being denser than the binder (HTPB, or Wax, or others).

\subsubsection{Effect of additives on combustion and regression rate}

Most of the studies have been made with polymeric binders and often at low pressure; the effect of pressure is generally not mentioned. The basic reference document on the subject is Risha [1, pp. 414-56].

\section{Conventional ballistic catalysts}

The increase of burning rates due to addition of catalysts $\left(\mathrm{CuC}_{12}, \mathrm{~K}_{2} \mathrm{Cr}_{2} \mathrm{O}_{7}\right.$, ferrocene) is in the range of $5 \%-25 \%$.

\section{Aluminum}

In the 1960s, the U.S. Air Force made a significant effort to develop a hybrid rocket as a viable alternative to liquid and solid rocket propulsion systems $[17,18]$ and tested aluminized fuels. The sizes of the particles traditionally used in the early development of hybrid rockets were usually on the order of micrometers, with the smallest size of $2-5 \mu \mathrm{m}$. The greater energy release from the oxidation of metal particles increased substantially the regression rate compared to nonmetallized solid fuels. With this apparent benefit in mind and recent advances in nanotechnology, nanosized particles possess the capability of releasing the energy in a shorter time and at a closer distance from the regressing fuel surface. There are many other direct advantages for incorporating nanosized particles into solid 
fuels and fuel-rich propellants. Nevertheless, the major conclusion is that aluminum is not the good solution to increase dramatically the burning rate that remains at the level of $1 \mathrm{~mm} / \mathrm{s}$ with oxygen associated with HTPB $(62 \%$ burning rate increase) or with any polymeric binder. There are few results with waxes where the basic burning rate is greater by a factor of 2.5-3.5 [3] "Regression rate (of waxes) appear promising for an operational use."

\section{Hydrides}

One major advantage of hydrides is the fast deshydrogenation under a thermal flux, then hydrogen will burn with the oxidizer and the binder gases in the primary flame zone, "the deshydrogenation of $\alpha$-Alane takes place on a time scale of at most $100 \mu \mathrm{s}$ " [19]. So, it will lead to a good combustion and a high regression rate. The work of the Politechnico di Milano confirms this trend [20].

Figure 10 shows the very important effect of addition of hydrides on the burning rate: addition of $11.2 \%$ Alane to the fuel $(5 \%$ of the global amount of propellant) increases the regression rate by a factor of 2.5 , the optimum amount is $70 \%$ of the fuel (35\% of the propellant).

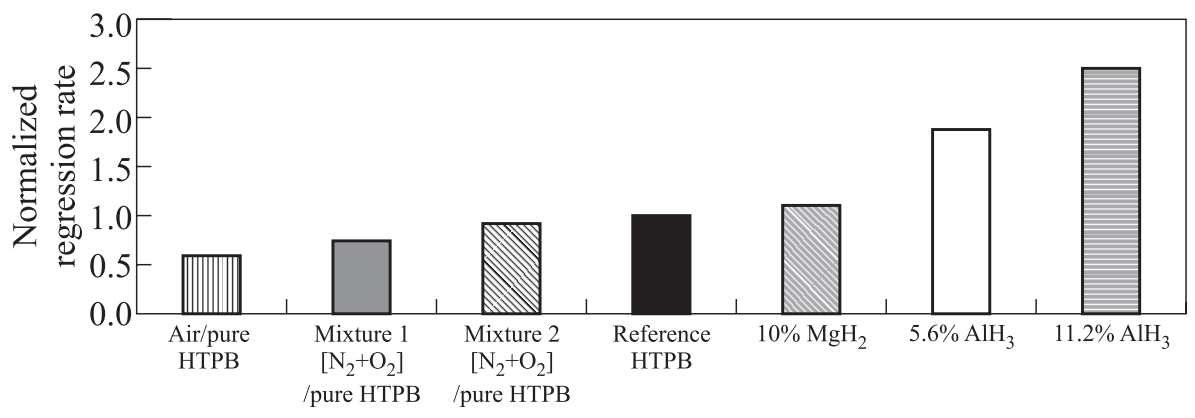

Figure 10 Fuel grain composition (SPLab)

\section{EUROPEAN HARDWARE STATE-OF-THE-ART}

The hardware needed to realize a Hybrid booster is perfectly in the state-of-theart of the European industry. The technologies of liquid part depend on the stage size and on the selected oxidizer, the practical possibilities of choice for the oxidizer are very limited. The family of nitric acid and MON used at the beginning of the development of sounding rockets is now generally discarded for safety reasons. LOx is the most powerful cryogenic oxidizer except for Fluorine whose mixtures and compounds are too dangerous to use. Hydrogen peroxide may be useful for missions requiring long-term storage in space. $\mathrm{N}_{2} \mathrm{O}$ (nitrous oxide) 
is storable, nontoxic, relatively friendly to use and, therefore, preferred for the Space Ship One. Thus, the technologies for liquid storage are coming from the shelf. Small and most large-scale hybrid motors have been tested with pressurefed systems (LEX, Volvo, NAMO, Firebolt, Space Ship One) with metallic tank or with a composite tank for the Space Ship One. Larger stages may need to be powered by a pump feed system. Such systems were developed only in the U.S., e. g., AMROC, Allied System Aerospace, and NASA SSC. In terms of hardware, the metallic tank solutions are similar to those used in Europe in the Ariane program. In case of a pressure-fed system, large composite tanks can be realized by several companies (with a metallic liner). The Ariane 5 industrial partners have all the know-how to realize the liquid storage (pressurization system, tank, turbopump if any, injection valve, etc.). For the solid storage/combustion chamber, a composite tank is generally to be used in modern large solid stages (use of a metallic case is interesting for only very small diameter rockets). As for the liquid part, among the potential players, the Ariane industrials in charge of the P250 have the technologies needed for the development.

\section{CONCLUDING REMARKS}

The specific feature of hybrid propulsion is to use the state-of-the-art of both liquid and solid propulsion; the only show stopper is the propellant itself. The past work focused on LOx/HTPB (selected for its low cost) appears to be a deadend (combustion problems and global low performances resulting from a high level of residuals). The solution that appears from the past experience is the addition of hydrides to a binder (HTPB or other) or a homogeneous fuel, or a mixture of both, with or without others additives. Within these solutions, some will not present any manufacturing problem and some may have a low cost. Nevertheless, the following studies have to demonstrate the compatibility of the potential regression rate range with a high-performance global design of a stage and the manufacturing at a reasonable cost of a hydride giving a high level of performances.

\section{REFERENCES}

1. Handbook of astronautical engineering. 1961. 1st ed. Koelle: Mc Graw Hill. 2015055.

2. Altman, D. 2003. Highlights in hibrid rocket propulsion. In: In-space propulsion. 10th IWCP Proceedings.

3. Kuo, K. K., and M. Chiaverini, eds. 2007. Fundamentals of hybrid rocket combustion and propulsion. Progress in astronautics and aeronautics ser. Reston, VA: AIAA. 218. 
4. Calabro, M. 1991. History of the European hybrids. AIAA Propulsion lecture ser. Reno, NV.

5. Altman, D., and A. Holzman. 2006. Overview and history of hybrid rocket propulsion. In: Fundamentals of hybrid rocket combustion and propulsion. Eds. M. Chiavernini and K. K. Kuo. Progress in astronautics and aeronautics ser. Reston, VA: AIAA. 218:Ch. 1.

6. ESTEC. 2000. EADS propulsion.

7. Martin, F. 2004. Cnes Séminaire Propulsion Hybride. Astrium.

8. Calabro, M. 2003. LOx/HTPB/AlH 3 hybrid propulsion for launch vehicle boosters. AIAA Paper No. 04-3823.

9. Boardman, T. A. 1997. Design and test planning for a $250 \mathrm{klbf}$ thrust hybrid rocket motor. AIAA Paper No. 97-2804.

10. Boardman, T., T. M. Abel, S.E. Claflin, et. al. 1997. Design and test planning for a 250-Klbf-thrust hybrid rocket motor under the hybrid propulsion demonstration program. AIAA Paper No. 1997-2804.

11. Sutton, G. 1992. Rocket propulsion elements. In: An introduction to the engineering of rockets. 7th rev. ed. New York: Wiley. Ch. 1.

12. Estey, P. N., and B. G. R. Hughes. 1992. The opportunity for hybrid rocket motors in commercial space. AIAA Paper No. 92-3431.

13. Mc Donald, A. J. 1992. Chemical rocket propulsion and the environment. AIAA Paper No. 1992-1660.

14. O. Orlandi, D. Theil, J. Saramago, P. G. Amand, F. Dauch, and P. Gautier. 2011. Various challenging aspects of hybrid propulsion. In: Progress in propulsion physics. Eds. L. DeLuca, C. Bonnal, O. Haidn, and S. Frolov. EUCASS advances in aerospace sciences book ser. TORUS PRESS, EDP Sciences. 2:375-88.

15. Calabro, M. 2002. Coupled optimization between launch vehicle and large SRB. Advanced Solid Rocket Technologies Short Course. Indianapolis, USA.

16. Lengellé, G. 2003. Hybrid propulsion Onera DEFA/L 66.

17. Smoot, L. D., and C. F. Price. 1966. Regression rates of metalized hybrid fuel systems. AIAA J. 4:910-15.

18. Mead, F. B., Jr. 1995. Early developments in hybrid propulsion technology at the Air Force Rocket Propulsion Laboratory. AIAA Paper No. 1995-2946.

19. Glumac, N., H. Krier, T. Bazyn, and R. Eyer. 2003. 9-IWCP novel energetic materials and applications. In: The combustion characteristics of aluminum hydride. Lerici.

20. De Luca, L. T., L. Galfetti, F. Maggi, and G. Colombo. 2009. Advances in hybrid rocket propulsion. 3rd Eucass Conference. Versailles. France. 